\title{
The Epidemiology of Invasive Meningococcal Disease in the Kingdom of Saudi Arabia: A Narrative Review with Updated Analysis
}

\author{
Selim Badur • Mona A. Al Dabbagh · Atef M. Shibl · Fayssal M. Farahat • \\ Serdar Öztürk · Debasish Saha · Mansour Khalaf
}

Received: April 2, 2021 / Accepted: May 24, 2021 / Published online: August 14, 2021

(c) GlaxoSmithKline Biologicals SA 2021

\section{ABSTRACT}

Reducing invasive meningococcal disease (IMD) through MenACWY immunization is a critical healthcare strategy in the Kingdom of Saudi Arabia (KSA). Robust IMD surveillance is essential to help assess the need for additional immunization initiatives in target populations.

Supplementary Information The online version contains supplementary material available at https:// doi.org/10.1007/s40121-021-00467-x.

\section{S. Badur $(\bowtie)$}

EM, Vaccines Scientific Affairs and Public Health, GSK, Büyükdere Caddesi No:173, 1, Levent Plaza B Blok, 34394 Istanbul, Turkey

e-mail: selim.x.badur@gsk.com

\section{A. Al Dabbagh}

Division of Infectious Diseases, Department of Pediatrics, King Abdulaziz Medical City, King Abdullah International Medical Research Centre, King Saud Bin Abdulaziz University for Health Sciences, Jidda, Saudi Arabia

A. M. Shibl

College of Medicine, Alfaisal University, Riyadh, Saudi Arabia

F. M. Farahat

Infection Prevention and Control Program, King Abdulaziz Medical City, King Saud Bin Abdulaziz University for Health Sciences, King Abdullah International Medical Research Center, Ministry of National Guard Health Affairs, Jidda, Saudi Arabia
This is particularly important in KSA, where mass gatherings accompanying Hajj/Umrah pilgrimages have been associated with IMD outbreaks within the local KSA population, and subsequent intercontinental spread via returning pilgrims. This narrative review of the published literature describes the changing epidemiology of IMD in KSA to provide a perspective on the impact of current immunization strategies and potential gaps. As recent published surveillance data are lacking, we also evaluated publicly reported data from the KSA

\section{S. Öztürk}

Medical \& Clinical Emerging Markets, GSK, Istanbul, Turkey

\section{Saha}

Clinical Research and Development, GSK, Wavre, Belgium

\section{Khalaf}

EM Central Vaccines Medical/Clinical, GSK, Jidda, Saudi Arabia 
Ministry of Health (MoH) for 2012-2019 to inform more recent IMD trends. Between 1995 and 2011, national surveillance data indicate that 1103 IMD cases were reported in KSA: 60\% in 2000-2001, involving two (mainly MenW) outbreaks involving KSA citizens/residents and pilgrims focused in Mecca and Medina. Across 2002-2011, 184 cases of IMD were reported, with a higher proportion occurring in KSA citizens/residents, and with less focus within pilgrimage centers than apparent in previous years. Our analysis of $\mathrm{MoH}$ data found that, between 2012 and 2019, 44 IMD cases were reported, all in KSA citizens/residents, and chiefly in children or infants. No pilgrimageassociated outbreaks have occurred since 2001. Serogroup data were available for $62.5 \%$ of all cases for 2002-2011; MenW (40.0\%), MenA (35.7\%), and MenB (16.5\%). Serogroup data for 2012-2019 remain incompletely reported, and the existing surveillance system could be improved, as some element of underestimation/ underreporting of IMD may exist. While existing MenACWY immunization strategies for KSA citizens/residents and visiting pilgrims have been successful in reducing IMD due to specific serogroups, disease due to MenB remains a potential risk, and additional immunization strategies should be considered.

Keywords: Bacterial meningitis; Epidemiology; Hajj; Kingdom of Saudi Arabia; Mass gathering; Meningococcal disease; Neisseria meningitidis; Outbreaks; Surveillance

\section{Key Summary Points}

\section{Why carry out this study?}

Immunization against invasive meningococcal disease (IMD) using the MenACWY vaccine is a key public health strategy in the Kingdom of Saudi Arabia (KSA). National surveillance to monitor epidemiologic trends is important to help identify benefits and unmet needs in current immunization strategies.
This narrative review describes the epidemiology of IMD in KSA drawn from previously published national surveillance data, supplemented by an appraisal of more recent data for 2012-2019.

\section{What was learned from the study?}

Introduction of MenACWY immunization has led to substantial declines in IMD since 2002, both in the local population and in visitors on Hajj/Umrah pilgrimages. From 2002-2011, 184 cases of IMD were reported, chiefly due to MenW, MenA, and MenB. Between 2012-2019, 44 cases were reported. Although serogroup data are limited, sporadic disease due to MenB and MenW is reported.

Appraisal of available surveillance data indicates that the existing surveillance system could be strengthened. As disease due to MenB remains a potential risk, additional immunization strategies should be considered.

\section{DIGITAL FEATURES}

This article is published with digital features, including a summary slide, to facilitate understanding of the article. To view digital features for this article go to https://doi.org/10.6084/ m9.figshare.14636118.

\section{INTRODUCTION}

Invasive meningococcal disease (IMD) due to Neisseria meningitidis infection is a leading cause of bacterial meningitis, with the annual global burden estimated to be 1.2 million cases, with approximately 335,000 deaths [1,2]. While 12 encapsulated serogroups have been identified [3], 6 serogroups are responsible for the great majority of IMD: serogroups A, B, C, W, X, and $\mathrm{Y}$, with the relative importance of specific 
serogroups showing substantial geographic and temporal variation $[1,2,4]$.

Development and subsequent introduction of meningococcal vaccines in global immunization strategies and country national immunization programmes (NIPs) has resulted in substantial reductions in IMD and have also contributed to shifts in predominant diseasecausing serogroups in different countries and regions [1, 5-9]. A broad range of vaccines are available, including those directed against single specific serogroups (MenA, MenC) and quadrivalent vaccines (MenACWY vaccine), providing broader protection $[1,6]$. More recently, protein-based vaccines (4CMenB and MenB-FHbp) against a range of subcapsular antigens conferring protection against MenB are now in use, $[1,10,11]$, with putative protection against other meningococcal strains [12]. In addition to direct protection of vaccine recipients, conjugated MenA, MenC, and MenACWY vaccines may reduce acquisition of nasopharyngeal carriage and so provide some degree of indirect or herd protection to the broader population $[6,13]$, although recent data question the degree of indirect protection seen with MenACWY vaccines [14].

Knowledge of local epidemiology through surveillance is essential to help identify where further immunization initiatives are necessary to provide a broader and more effective protection to the local populations. Many countries across Europe, the Americas, and elsewhere, e.g., Australia, have robust surveillance systems with the capacity to evaluate IMD cases and incidence rates, and to respond to changing IMD epidemiology in adopting more robust, clinically relevant immunization strategies [15-22]. However, the strength of IMD surveillance and the availability of published epidemiological data vary considerably worldwide. Most global reviews, including regional reviews from the Global Meningococcal Initiative, highlight limited recent epidemiological data available from many countries in Asia, and from the Middle East and North African (MENA) regions. [1, 2, 23-25].

This is also apparent for the Kingdom of Saudi Arabia (KSA), the focus of the present manuscript, where IMD epidemiology has an added complexity, as the country experiences a substantial influx of overseas visitors each year, attending the annual Hajj pilgrimage held at a specific date each year (from the 8th to the 13th day of the 12th month, "Dhu al-Hijjah", in the Islamic calendar), or those making the Umrah pilgrimage which can take place at any time throughout the year, although with a peak during the month of Ramadan (almost 2 months before the Hajj season) [26, 27]. More than 2 million visitors enter the KSA for Hajj each year, and a far greater number for Umrah (7.2 million in 2019) [28]. Mass gatherings that accompany the Hajj and Umrah pilgrimages have been associated with a number of Hajj-related IMD outbreaks within the local KSA population: notably, those due to MenA in 1987 and $1992[29,30]$, and two outbreaks due predominantly to MenW in 2000 and 2001 $[31,32]$. In addition to the local impact, these outbreaks, and particularly those due to MenW, have been associated with intercontinental spread through pilgrims acting as vectors for outbreaks in the pilgrims' homelands on their return [33, 34].

Much of the recent relevant literature from KSA focuses on the pilgrimage aspects of IMD and associated meningococcal immunization policies [26, 35-38]. However, while more specific national surveillance data have been fully reported for a period spanning the years 1995-2011 [39, 40], and more recent data reported by the KSA Ministry of Health $(\mathrm{MoH})$ are available [41], a clear presentation of more recent trends in epidemiological data are lacking. A more complete understanding of IMD within KSA can provide a valuable perspective on the benefits and unmet needs of current vaccination strategies. It also provides an important benchmark to evaluate the country's progress and contribution towards the World Health Organisation's global aim to eliminate meningitis worldwide by $2030[42,43]$.

In this narrative review, we describe the changing epidemiology in KSA, drawing from previously reported surveillance data for 1995-2011 [40], updated with the more recent data reported by the KSA MoH [41]. For context, we also describe relevant aspects of IMD 
surveillance and existing immunization strategies.

\section{DATA SOURCES}

To inform this review, we used two complementary approaches; first, reviewing the relevant previously published literature, and, second, evaluating recent national data formally reported by the KSA MoH [41]. As a starting point, we performed a comprehensive literature review searching PubMed electronic databases using search terms relating to meningitis and meningococcal disease in KSA and the Haji and Umrah pilgrimages (Supplementary data). Note that, while comprehensive, our literature search was not systematic. The purpose was to identify relevant publications reporting IMD epidemiology to help present a coherent picture of the IMD disease burden in the KSA population, the vaccine policy, and pertinent aspects of IMD in pilgrims, rather than to catalogue and perform a critical appraisal of the published literature per se (although some general observations could be and have been made).

Our search and subsequent appraisal identified gaps in recent published literature on IMD epidemiology in the KSA. While comprehensive surveillance data have been fully reported for a period spanning the years 1995-2011 [39, 40], there is a lack of more recent published epidemiology. As such surveillance data are publicly reported by the $\mathrm{MoH}$ as part of its annual reports on health statistics, we examined the available data on all meningitis, and in particular IMD, and extracted all relevant statistics for the period 2012-2019 [41]. For context, this included the absolute number of all reported meningitis cases per year stratified by causative organism [IMD, pneumococcal meningitis, Haemophilus influenzae type b (Hib) and 'other'] and their respective annual incidence per 100,000 inhabitants. For IMD, we also evaluated case numbers and annual incidence for the overall population, and also stratified by age group, gender/sex, resident status (Saudi or non-Saudi national), and case distribution by region.
In compliance with ethical guidelines, we wish to state that this article is based on previously conducted studies and reported data, and does not contain any studies with human participants or animals performed by any of the authors.

\section{SURVEILLANCE ASPECTS}

Before reporting on IMD epidemiology, some description of the IMD surveillance system in KSA, population characteristics, and immunization policies can help place these data in context.

\section{IMD surveillance in KSA}

IMD surveillance in KSA is based on immediate mandatory reporting of all clinically suspected meningitis cases to the regional health authority, which is responsible for immediate preventive measures (antibiotic prophylaxis of close contacts through contact tracing), and which oversee clinical and laboratory confirmation. Case confirmation for bacterial meningitis is on the basis of isolation of a causative organism $(N$. meningitidis, S. pneumoniae, $H$. influenzae, etc.) from the cerebrospinal fluid (CSF) or by blood culture, and/or detection of bacterial antigens in the CSF via latex agglutination. Increasingly, polymerase chain reaction (PCR) technologies are used to identify organisms from CSF and blood samples (particularly useful in culturenegative samples). For IMD, causative serogroups are determined using latex agglutination and PCR. For each case, all relevant clinical, microbial, and demographic aspects (age, gender, resident status, etc.) are recorded on a casereporting form, and then shared by the regional health authority with the $\mathrm{MoH}$ [40]. These data form the basis of data published by the $\mathrm{MoH}$ in their statistical yearbooks [41]. While these datasets are publicly available, there are some limitations to the data. For example, while the surveillance parameters outlined above clearly allow for identification and categorization of different clinical forms (i.e., meningococcal meningitis, meningococcal bacteremia/septicemia, or meningococcal meningitis plus 
bacteremia) and rarer presentations (e.g., septic arthritis), such information is not reported in the statistical yearbooks.

\section{Population characteristics}

Over the past 25 years, there have been substantial increases in the overall population of KSA, rising from 18.5 million in 1995 to 27.5 million in 2011 [40], and to 35.2 million in 2019 [41]. Illustrative population demographics are shown in Tables S1 and S2. A substantial number of residents are non-Saudi nationals living and working in KSA, representing $30-40 \%$ of the overall population, and accounting for $38 \%$ of the total population in 2019 [41]. While the Saudi national population comprises similar numbers of males and females, there are approximately twice the number of resident (non-Saudi) males than females, and so at present males constitute approximately $58 \%$ of the overall KSA population [41].

In 2019, individuals aged from 15 to 64 years constitute $72.3 \%$ of the population, $16.2 \%$ are aged from 5 to 14 years and $8.3 \%$ are children $<5$ years of age [41]. At present, $25.3 \%$ of the population reside in Riyadh; other important regional population centers are Jeddah (14.3\%), Mecca (7.2\%), and Medina (6.5\%) (Table S2).

\section{IMD immunization in KSA}

Immunization strategies implemented by the KSA MoH have been heavily influenced by disease epidemiology within KSA itself (including IMD outbreaks associated with the Hajj pilgrimage), and also by the development and introduction of available vaccines. These strategies address protection in the local KSA resident population and also for pilgrims entering KSA for Hajj or Umrah purposes. The evolution of IMD immunization approaches and key policy changes has been comprehensively reviewed by Yesli and colleagues, from which we describe the key developments [35].

Initially, immunization was introduced in response to an outbreak of MenA disease in
1987, after which mandatory immunization with the bivalent MenAC vaccine was introduced for all pilgrims attending the Hajj, along with vaccination initiatives directed towards KSA residents in the major pilgrimage sites of Mecca and Medina. For those pilgrims attending from the high-risk Sub-Saharan meningitis belt, an additional step was compulsory use of oral ciprofloxacin on arrival in KSA in order to reduce $N$. meningitidis nasopharyngeal carriage. A broader protective policy was implemented in 2002, following significant outbreaks due to serogroup W in 2000 and 2001, again associated with Hajj gatherings (both within KSA and in pilgrims returning to their country of origin), with compulsory vaccination with the polysaccharide quadrivalent MenACWY vaccine required by all citizens/residents in and around Mecca/Medina and all Hajj pilgrims $\geq 2$ years of age, as well as immunization of all healthcare workers, and personnel involved in pilgrimage activities. In 2010, the use of conjugated MenACWY vaccine was introduced within KSA for use in individuals aged 2-55 years, while the polysaccharide ACWY vaccine remains valid for older citizens/residents and all external pilgrims [35]. Since 2013, the NIP has included infant vaccination with conjugated MenACWY vaccine (at 9 and 12 months), and more recently has since 2020 recommended a single dose to be given at 18 years of age [44, 45]. Vaccination against other important causes of infant meningitis (S. pneumoniae and $H$. influenzae) is also included in the NIP (with pneumococcal immunization given at 2, 4, 6, and 12 months of age, and Hib at 2, 4, 6, and 18 months) [45]. Although infant MenACWY vaccination coverage is not reported within the publicly available $\mathrm{MoH}$ datasets, the uptake of other recommended infant vaccines is reported to be high (>95\%) in recent years for hexavalent (diphtheria, pertussis, tetanus, Hib, hepatitis $\mathrm{B}$, and polio) pneumococcal and measles-mumps-rubella vaccines [41]; one might assume that infant MenACWY coverage is also high.

At the present time, external pilgrims are required to show evidence of prior meningococcal vaccination before entry into the country (within the past 5 years for those immunized with conjugated MenACWY vaccines, and 
within the past 3 years for polysaccharide MenACWY vaccines) [46]. Similar requirements also apply to all citizens/residents in Mecca/ Medina, all internal pilgrims, and all staff working with the pilgrims; compliance is facilitated by annual vaccination campaigns offering primary and booster dosing as necessary [35]. While MenB vaccines are now available and used in a number of other countries in their national immunization schedules [1, 10, 11], Men $B$ vaccination is not included in current immunization strategies in KSA, or for individuals entering the country for the Hajj and Umrah pilgrimages [36, 46, 47].

\section{EPIDEMIOLOGY OF IMD IN KSA}

\section{IMD surveillance 1995-2011}

Two key surveillance studies have reported on IMD within KSA across this period, each of which is based on data reported in $\mathrm{MoH}$ sources. The first study reported on all IMD cases for the years 1999-2002, a period covering disease outbreaks due to serogroup $\mathrm{W}$ associated with overseas pilgrims attending for Hajj or Umrah in 2000 and 2001 [39]. A subsequent and more comprehensive review by Memish et al. evaluated surveillance across a broader period, from 1995 to 2011 [40], from which we describe key aspects.

Over this 1995-2011 period, 1103 IMD cases were reported, of which 645 occurred in KSA citizens or residents (Fig. 1). Note that no distinction between the different clinical forms of IMD (meningococcal meningitis, septicemia, or meningitis plus septicemia) was reported. For KSA citizens/residents, the highest cumulative incidence across 1995-2011 was seen in children $<5$ years of age $(12 / 100,000)$; cumulative incidence was $2 / 100,000$ in those aged 5-14 years, and approximately $1 / 100,000$ in both the 15-64 and $\geq 65$ years age-groups.

Looking at specific timeframes; 265 cases occurred between 1995 and 1999 [of which 139 $(52.4 \%)$ occurred in KSA citizens or residents], 654 cases in the 2000-2001 period which included the Hajj-related IMD outbreaks [372 $(56.9 \%)$ in KSA citizens/residents), and 184 cases from 2002 to 2011 [134 (72.8\%) in KSA citizens/residents] [40]. In the 2002-2011 period, while approximately 50 cases were reported in KSA residents in 2002 and 2003, in later years the annual case numbers declined to around 10 cases each year. Surveying the population-adjusted annual incidence rates for KSA citizens/ residents for these periods, between 1995 and 1999 , the mean annual incidence in the overall population was $0.20 / 100,000$, rising to $1.42 /$ 100,000 and 1.32/100,000 in the peak 2000 and 2001 years, respectively, and then declining from $0.21 / 100,000$ in 2002 to $0.01 / 100,000$ in 2010 [40].

From a geographical perspective, approximately $49 \%$ of all cases in 2000 occurred in Mecca and Medina during Hajj (and approximately $31 \%$ of all cases in 2001), while, in the
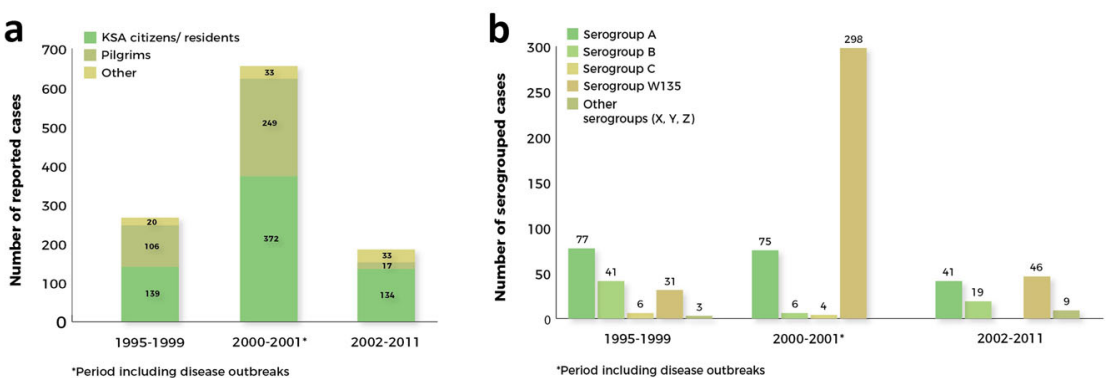

Fig. 1 IMD in KSA (1995-2011). Case numbers and prevalence of $N$. meningitidis serogroups in KSA across 3 different periods; 1995-1999, 2000/2001 (which includes outbreaks associated with Hajj), and 2002-2011. a All

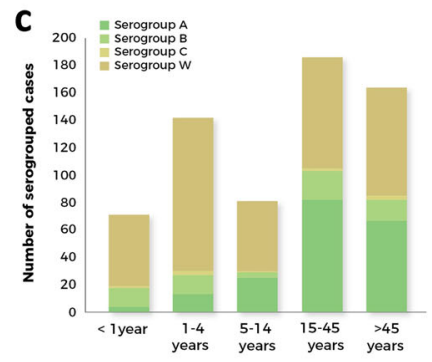

reported IMD cases. b Serogroup cases. c Serogroup distribution by age strata (1995-2011). Adapted from previously reported data [40]. IMD invasive meningococcal disease; KSA Kingdom of Saudi Arabia 
2002-2011 period, these cities together accounted for only $8.1 \%$ of reported cases occurring during the Hajj seasons [40]. This would seem to reflect the decreasing impact of outbreaks associated with mass gatherings, with no IMD outbreaks occurring within KSA since 2001.

To some extent, the age-related epidemiology across this period reflects the age demographics of at-risk populations, where broadly speaking the mean age of non-Saudi nationals is higher than Saudi national citizens and higher still in visiting pilgrims. The mean age of IMD cases across the entire 1995-2011 period was lowest in Saudi national citizens (9.6 years), higher in non-Saudi national residents (14.4 years), and much higher in Hajj-pilgrims ( 48.9 years). In addition, the mean age of IMD cases was also higher during Hajj seasons, and, in cases occurring in Mecca and Medina compared to other times of the year or regions, in part reflecting the influence of cases in (generally) older pilgrims. Finally, the general pattern across this whole period was that of a decrease in the age of IMD cases, falling from a mean age of 31 years in 1995-1999 to 18 years in 2002-2011, which in part reflects the increasing contribution of KSA citizens/residents to the total IMD case numbers and the relative decline in case numbers in pilgrims.

Mortality due to IMD was high, with 198 deaths across 1995-2011, and an overall case fatality rate (CFR) of $18.0 \%$ [40]. The majority of deaths $(125,63.1 \%)$ occurred in external pilgrims visiting for Hajj or Umrah, and the CFR was substantially higher $(28.9 \%)$ in external pilgrims than in KSA citizens/residents (10.4\%); CFRs were also higher in IMD cases occurring during the Hajj season $(28.6 \%)$ than at other times $(10.0 \%)$. This in part may reflect delay in diagnosis and medical care in patients on pilgrimage, and also the generally greater age of pilgrims. Looking at age-related IMD mortality, most occurred in older age groups, with 85 deaths in those aged $>45$ years and 72 deaths in those aged 15-45 years; 8 IMD deaths occurred in children $<1$ year of age, 20 deaths in those aged 1-4 years, and 13 in those aged 5-14 years. Higher CFRs were seen with increasing age, being lowest in infants $<1$ year $(6.8 \%), 9.4 \%$ in individuals aged between 1 and 4 years, 9.3\% in those aged 5-14 years, $19.4 \%$ in those aged $15-45$ years, and $32.6 \%$ in those $>45$ years. However, this pattern also changed over time. While the annual mean CFR in children $<5$ years of age was relatively similar in 1995-1999 and in 2002-2011 (13.6\% and $12.4 \%$, respectively), the CFR in patients aged $\geq 5$ years fell from $20.7 \%$ in $1995-1999$ to $8.7 \%$ in 2002-2011 [40], which may reflect the generally lower mean age of non-infant cases in this latter period that we outline above.

For the complete 1995-2011 period, a total of 656 cases (59.5\%) had serogroup data [40]. Of these cases, $11.3 \%$ occurred in infants $<1$ year, $21.8 \%$ in those aged $1-4$ years, and $13.1 \%$ in those aged 5-14 years. The greatest number of cases were due to MenW (57.2\%) and MenA (29.4\%), while MenB accounted for $10.1 \%$ of cases. However, serogroup distribution varied across this period (Fig. 1). Between 1995 and 1999, MenA and MenB were the most prevalent serogroups, while in 2000-2001, the high numbers of MenW and MenA cases reflect the impact that the disease outbreaks in these years associated with the Hajj (chiefly a MenW outbreak, although a MenA outbreak also occurred in 2000). Subsequently, between 2002 and 2011 , of the $115 / 184$ IMD cases $(62.5 \%)$ with serogroup data, $40.0 \%$ were MenW, $35.7 \%$ were MenA, and $16.5 \%$ were due to MenB, with a few cases due to other serogroups (i.e., MenY, MenX, and MenZ). There were no notable differences in CFRs associated with the principal causative serogroups: MenA (21.8\%), MenB $(21.2 \%)$, and MenW (19.7\%), although a higher CFR was seen in the small number of cases due to MenY (33.3\%) [40].

\section{Updated surveillance 2012-2019}

Our updated surveillance data for subsequent years are outlined as follows. Between 2012 and 2019 , there was a total of 2050 meningitis cases reported by the $\mathrm{MoH}$ [41]. Of these, the great majority were categorized as 'other', a group that includes culture-negative disease and viral and 'aseptic' meningitis, accounting for 1875 cases $(91.5 \%)$ (Table 1; Fig. 2a). Looking at 
Table 1 Epidemiology of meningitis and IMD in KSA (2012-2019)

\begin{tabular}{|c|c|c|c|c|c|c|c|c|c|}
\hline & 2012 & 2013 & 2014 & 2015 & 2016 & 2017 & 2018 & 2019 & 2012-2019 \\
\hline \multicolumn{10}{|l|}{ All meningitis } \\
\hline Meningococcal & 4 & 2 & 4 & 6 & 6 & 10 & 9 & 3 & 44 \\
\hline Pneumococcal & 3 & 3 & 2 & 5 & 14 & 39 & 27 & 6 & 99 \\
\hline H. influenzae & 1 & 3 & 1 & 3 & 2 & 8 & 9 & 5 & 32 \\
\hline Other & 215 & 293 & 189 & 171 & 243 & 358 & 187 & 219 & 1875 \\
\hline Total & 223 & 301 & 196 & 185 & 265 & 415 & 232 & 233 & 2050 \\
\hline \multicolumn{10}{|l|}{ IMD } \\
\hline Incidence/100,000 & 0.01 & 0.01 & 0.01 & 0.02 & 0.02 & 0.03 & 0.03 & 0.01 & 0.02 \\
\hline \multicolumn{10}{|l|}{ Demographics } \\
\hline \multicolumn{10}{|l|}{ Age-strata } \\
\hline$<1$ year & 1 & - & 1 & 1 & - & 3 & 1 & - & 7 \\
\hline $1-4$ years & - & 1 & - & 2 & 1 & - & 2 & 1 & 7 \\
\hline $5-14$ years & 1 & 1 & 2 & 3 & 1 & 3 & 2 & 2 & 15 \\
\hline $15-44$ years & 2 & - & 1 & - & 2 & 1 & 2 & - & 8 \\
\hline$\geq 45$ years & - & - & - & - & 2 & 3 & 2 & - & 7 \\
\hline \multicolumn{10}{|l|}{ Gender } \\
\hline Male & 2 & 2 & 3 & 4 & 5 & 6 & 3 & 2 & 27 \\
\hline Female & 2 & - & 1 & 2 & 1 & 4 & 6 & 1 & 17 \\
\hline \multicolumn{10}{|l|}{ Status } \\
\hline Saudi national & 2 & 2 & 4 & 1 & 6 & 7 & 8 & 1 & 31 \\
\hline Non-Saudi resident & 2 & - & - & 5 & - & 3 & 1 & 2 & 13 \\
\hline
\end{tabular}

Data represent those cases reported by the Ministry of Health [41]

$I M D$ invasive meningococcal disease; KSA Kingdom of Saudi Arabia

specific years in this period, more cases were reported in 2017 than other years, with 415 meningitis cases due to any cause, with the highest numbers of identifiable bacterial meningitis cases also reported in 2017 (Fig. 2a). The majority of all meningitis cases due to any cause occurred in children and adolescents $<15$ years of age $(62.5 \%)$; approximately one-third of all cases occurred in infants $<1$ year of age (Fig. 2b). A total of 175 confirmed bacterial meningitis cases were reported for 2012-2019, and the most common identifiable pathogen was $S$. pneumoniae (99 cases; $56.6 \%$ of all bacterial meningitis cases), followed by $N$. meningitidis (44 cases; $25.1 \%$ of all bacterial meningitis cases), and $H$. influenzae (32 cases; $18.3 \%$ of all bacterial meningitis cases) (Table 1; Fig. 2c). As described earlier, while such information is captured during surveillance, reporting limitations preclude reporting on the relative prevalence of different clinical forms of IMD (meningococcal meningitis or meningococcemia sepsis, or both together). Across 2012-2019, of the 44 IMD cases 

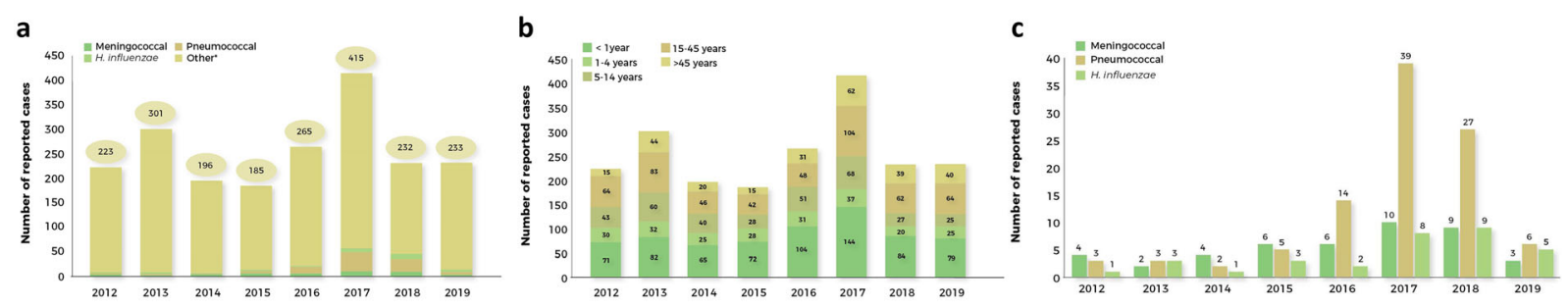

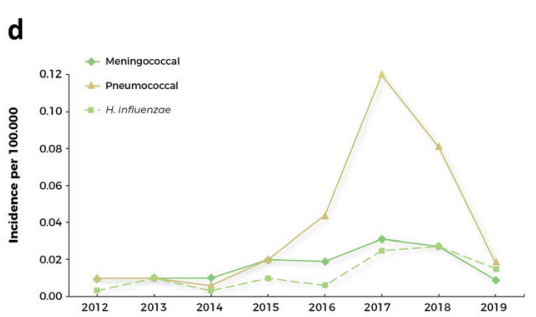

Fig. 2 Meningitis in KSA (2012-2019). a Annual number of meningitis cases by type (meningococcal, pneumococcal, $H$. influenzae, and 'other'. b Age distribution of all meningitis cases (2012-2019). c Number of vaccinepreventable meningitis cases. $\mathbf{d}$ Incidence of

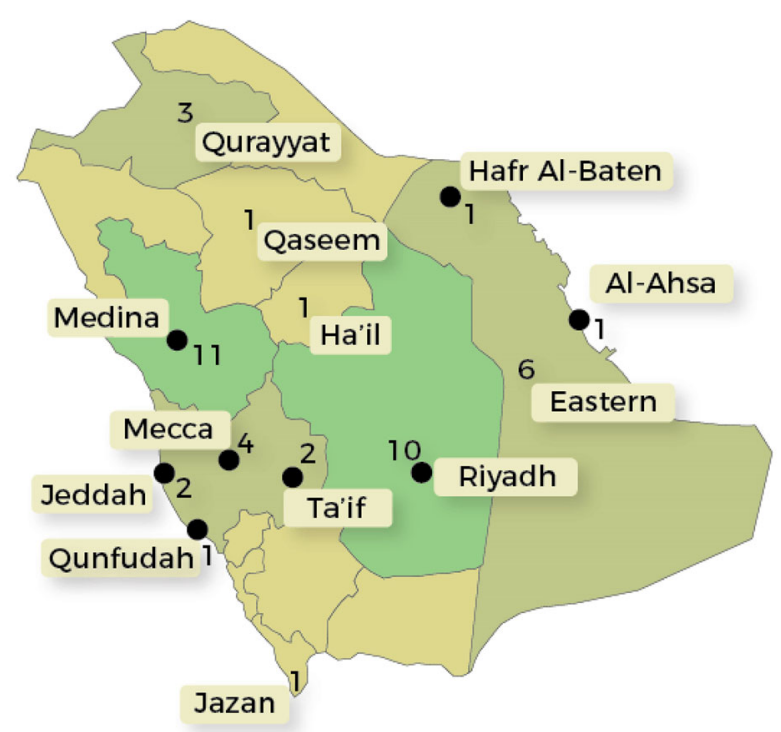

Fig. 3 Regional distribution of IMD cases in KSA (2012-2019). Data represent those cases reported by the Ministry of Health [41]. IMD invasive meningococcal disease; KSA Kingdom of Saudi Arabia

reported, the greatest number of IMD cases occurred in $2017(n=10)$ and $2018(n=9)$, while $65.9 \%$ occurred in children and

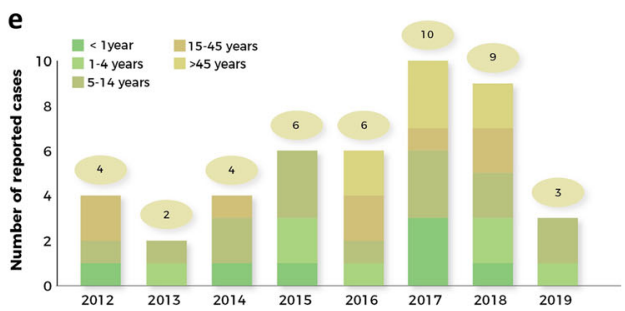

meningococcal, pneumococcal, and $H$. influenzae meningitis. e Age distribution of IMD cases. Data represent those cases reported by the Ministry of Health [41]. IMD invasive meningococcal disease; $K S A$ Kingdom of Saudi Arabia; $V P D$ vaccine-preventable disease

adolescents $<15$ years of age and $31.8 \%$ in children $<5$ years of age. Most cases were reported in Saudi citizens $(n=31)$ with 13 cases reported in non-Saudi residents, and 27 cases occurred in males; these latter numerical differences are generally consistent with the population demographics outlined above. The mean IMD incidence rate in the overall population for 2012-2019 was 0.02/100,000 (Table 1; Fig. 2c-e). The highest number of reported IMD cases was recorded in Medina $(n=11)$ and Riyadh $(n=10)$, while four cases were reported from Mecca (Fig. 3). No specific seasonal pattern to IMD cases was apparent (Fig. S1).

A limitation of reporting from this more recent $\mathrm{MoH}$ yearbook data for IMD is the lack of information on causative serogroup or mortality, while recent serogroup data reported from other sources are limited. Although Yesli et al. have reported that disease due to MenW, MenA, MenB, and MenY have all been reported to the $\mathrm{MoH}$ in the years 2012-2015, absolute numbers are lacking [26]. 


\section{DISCUSSION}

Our narrative review encompasses previously reported data complemented by our descriptive analysis of more recent national surveillance data from the KSA MoH. From these data, a broad pattern may be seen, with a higher incidence of endemic disease prior to the introduction of immunization strategies, disease outbreaks associated with the Hajj pilgrimage (in 1987, 1992, 2000 and 2001), and then a subsequent substantial decline in case numbers and incidence rates, with no outbreaks since 2001. Clearly the implementation of compulsory immunization with the quadrivalent ACWY vaccine in 2002 at a local level (in Mecca and Medina) and for all Hajj pilgrims has had some impact in reducing Haji-related IMD outbreaks, and in reducing the IMD burden in KSA citizens/residents. These benefits have been sustained with the broader policy of MenACWY immunization throughout KSA of individuals aged 2-55 years in 2010, and subsequent inclusion of infant vaccination within the NIP in 2013 , supplemented by adolescent vaccination at 18 years since 2020 .

This overall pattern, and the relatively low number of cases we report in our analysis of the more recent 2012-2019 $\mathrm{MoH}$ data, provide support for the existing immunization strategies implemented both in the KSA population and for visiting pilgrims. Nevertheless, immunization gaps exist in the current NIP: infant MenACWY vaccination at 9 and 12 months leaves younger infants unprotected, and earlier immunization could be considered. Similarly, younger adolescents remain unprotected until their scheduled immunization at 18 years (and with potential for transmission to unvaccinated younger infants). Earlier infant and adolescent immunization could potentially reduce the disease burden in these age groups. The absence of any requirement for visiting external pilgrims aged $<2$ years to be vaccinated with conjugated MenACWY is another consideration.

Other aspects of the current surveillance system, disease burden, and existing immunization strategies are worth further consideration.
One important point is that some level of underreporting for IMD in KSA may exist, a feature also apparent in other surveillance studies in the MENA regions [25, 48, 49]. We suggest this for two reasons. First, the high level of all meningitis cases in the 2012-2019 period categorized as 'other' (more than 90\%) may in part reflect antibiotic therapy implemented prior to a more complete diagnostic evaluation, and also inconsistent diagnostic approaches within KSA. In addition, it is worth commenting here on certain inconsistencies in IMD cases reported by the $\mathrm{MoH}$ and those reported in independent publications. A striking example is a recently published study evaluating inflammatory/immunological signals in patients admitted with febrile illnesses to a major hospital in the Jazan region, which reported on 52 cases of IMD in adults between January 2014 and December 2017, with disease due to $N$. meningitidis confirmed via bacterial culture [50]. All the patients were adults $\geq 18$ years (median 45 years, range $18-75$ years; $61.5 \%$ male). From the published data, it is not possible to confidently report on the number of cases each year, and no serogroup data were reported. While clinical data are limited, there were no IMD fatalities [50]. However, as we report above, there have been only 44 confirmed IMD cases reported nationwide in the 2012-2019 period, 29 of which occurred in children and adolescents aged $<15$ years. Furthermore, at the national level, only 26 IMD cases were reported across 2014-2017, and in Jazan no cases of IMD occurring across 2014-2017 were reported (and, indeed, just a single case from Jazan was reported by the $\mathrm{MoH}$ over the 2012-2019 period, which was in 2012, with none reported from 2013 onwards). It would seem, therefore, that these cases reported from Jazan have not been included in the data reported by the $\mathrm{MoH}$.

A second point is the scarcity of recent serogroup data. A more complete appraisal of IMD causative serogroups is necessary to fully assess the benefit of existing immunization strategies and to identify unmet needs such as strategies to prevent IMD due to MenB [36]. As we describe above, MenB was responsible for $16.5 \%$ of IMD cases between 2002 and 2011, and, albeit limited, data suggest it remains an 
important causative serogroup in more recent years [26]. Furthermore, as we describe below, carriage of MenB among pilgrims entering KSA is well documented [51].

These observations (potential underreporting, and limited serogroup data) would suggest that the present surveillance system for IMD in KSA and its reporting could be strengthened, echoing comments made previously by others evaluating KSA national surveillance data and regional surveillance systems [40, 52]. Strengthening existing surveillance, to include earlier notification of clinically suspected cases, use of standardized clinical and diagnostic criteria, greater application of molecular diagnostics, and more complete serogroup determination (and antibiotic susceptibility testing) can all contribute to improved diagnostic yield and aid clinical management. These could generate a more robust surveillance system to more accurately reflect the current epidemiology and epidemiological trends. Documentation of specific clinical presentations and forms of IMD (meningitis, bacteremia, or both) would also have value, and reporting of immunization coverage and also linkage of IMD cases to immunization status are also important, as is reporting of mortality data. While such data may be currently collected, the collection is not uniform, and these data are not reported in the publicly available $\mathrm{MOH}$ datasets.

While the focus of the present review is principally on IMD within KSA (and in the KSA citizen/resident population) a final consideration remains the broader relevance of the Hajj and Umrah pilgrimages. The impact and role of pilgrimages on global and local IMD epidemiology has been comprehensively reviewed in a number of recent publications and editorials $[26,35-38]$, and a detailed review is beyond the scope of the current manuscript. However, one broad theme that has emerged is that, while the existing vaccination policies (for external pilgrims and for the KSA population) have had substantial benefits, sporadic cases of IMD still occur, some of which may be due to other serogroups, such as MenB, and also less common serogroups (MenX and MenZ), none of which are covered by existing recommended vaccines. The introduction of $N$. meningitidis into local and pilgrim populations is one concern. Some data indicate that MenB is the dominant serogroup carriage in pilgrims. A prospective cohort study evaluating carriage in Hajj pilgrims arriving in Jeddah in 2014 reported meningococcal carriage in 36/1055 (3.4\%) of pilgrims, and in $8.9 \%$ of those from sub-Saharan Africa; $66.7 \%$ of isolates were MenB (the remainder being ungroupable) [51]. With approximately 2 million Hajj pilgrims and 8 million Umrah pilgrims entering the KSA annually, if these carriage rates were extrapolated to the overall pilgrim population, even if at a highly conservative manner, then it seems that there is a risk of substantial carriage of MenB into KSA. The role of pilgrims acting as a reservoir and transmission vector on their return home, and the development of antibiotic-resistant strains in returning pilgrims also remain a threat $[33,53,54]$. The recent emergence in Europe of IMD due to a ciprofloxacinresistant non-groupable Neisseria strain has been linked to immigrants or residents returning from overseas travel, including two cases from 2019 in Umrah pilgrims returning from Mecca [55]. While non-groupable strains are not covered by the quadrivalent MenACWY vaccines, limited genomic data suggest that some may be covered by subcapsular protein-based MenB vaccines [55].

This, along with our own observations, provides some support for MenB vaccination to be considered as an additional component to the existing vaccine policy in KSA, and for those participating in Hajj and Umrah pilgrimage events.

Finally, as the present coronavirus disease 2019 (COVID-19) global pandemic continues, there are as yet very limited data on its impact on IMD in KSA. A promising sign is that there seems to be little if any effect on vaccine uptake for those infant vaccinations with coverage reported by the $\mathrm{MoH}$ (all infant vaccines except MenACWY), with $>95 \%$ coverage for all in 2020 [56] These data report only 115 cases of any form of meningitis in 2020, of which there was only a single case of IMD (occurring in a child aged 1-4 years) [56]. These most recent data from the $\mathrm{MoH}$ for 2020 were reported during manuscript revision and form no part of 
the analyses we present. However, while we should be cautious about drawing any conclusions on any impact of the COVID-19 pandemic at this early stage, it would seem that the impact is minimal if any in terms of IMD.

\section{CONCLUSIONS}

Preventive measures implemented by the KSA $\mathrm{MoH}$, chiefly MenACWY vaccination targeted initially towards KSA residents at greatest risk along with all pilgrims entering KSA, with a subsequent broader national policy has led to substantial declines in IMD within KSA, with no significant pilgrimage-associated outbreaks. However, IMD remains a threat, with sporadic cases, mainly in infants and children $<15$ years, and some level of endemic disease (which may be underestimated). Assessing the true IMD burden requires strengthening of the existing surveillance system to monitor changing epidemiology due to specific serogroups and to measure vaccine uptake. This can help facilitate evaluation of existing MenACWY vaccine impact. At present, disease due to MenB remains a concern, both within KSA and in visiting pilgrims, and additional immunization strategies could be considered.

\section{ACKNOWLEDGEMENTS}

Funding. GlaxoSmithKline Biologicals SA funded this study and all costs related to the development and publication of this manuscript.

Medical Writing, Editorial, and Other Assistance. The authors would like to thank Business \& Decision Life Sciences platform for editorial assistance and publications coordination, on behalf of GSK. Amandine Radziejwoski coordinated publication development and editorial support. The authors also thank and Iain O'Neill (freelance on behalf of GSK) for providing medical writing support.
Authorship. All named authors meet the International Committee of Medical Journal Editors (ICMJE) criteria for authorship for this article, take responsibility for the integrity of the work as a whole, and have given their approval for this version to be published.

Authorship Contributions. All authors participated in the design or implementation or analysis, and interpretation of the study; and the development of this manuscript. All authors had full access to the data and gave final approval before submission.

Disclosures. Mansour Khalaf, Serdar Öztürk, Debasish Saha, and Selim Badur are employed by the GSK group of companies and hold shares in the GSK group of companies; they each declare no other financial and non-financial relationships and activities. Fayssal M. Farahat, Atef M. Shibl and Mona A. Al Dabbagh have nothing to disclose.

Compliance with Ethics Guidelines. This article is based on previously conducted studies and does not contain any studies performed by any of the authors with human participants or animals.

Data availability. All data generated or analyzed are included in this published article/ as supplementary information files or in the original data sources data $[40,41]$.

Open Access. This article is licensed under a Creative Commons Attribution-NonCommercial 4.0 International License, which permits any non-commercial use, sharing, adaptation, distribution and reproduction in any medium or format, as long as you give appropriate credit to the original author(s) and the source, provide a link to the Creative Commons licence, and indicate if changes were made. The images or other third party material in this article are included in the article's Creative Commons licence, unless indicated otherwise in a credit line to the material. If material is not included in the article's Creative Commons licence and your intended use is not permitted by statutory regulation or exceeds the 
permitted use, you will need to obtain permission directly from the copyright holder. To view a copy of this licence, visit http:// creativecommons.org/licenses/by-nc/4.0/.

\section{REFERENCES}

1. Parikh SR, Campbell H, Bettinger JA, et al. The everchanging epidemiology of meningococcal disease worldwide and the potential for prevention through vaccination. J Infect. 2020;81:483-98.

2. Peterson ME, Li Y, Bita A, Moureau A, et al. Meningococcal serogroups and surveillance: a systematic review and survey. J Glob Health. 2019;9: 010409.

3. Harrison OB, Claus H, Jiang Y, et al. Description and nomenclature of Neisseria meningitidis capsule locus. Emerg Infect Dis. 2013;19:566-73.

4. Jafri RZ, Ali A, Messonnier NE, Tevi-Benissan C, et al. Global epidemiology of invasive meningococcal disease. Popul Health Metr. 2013;11:17.

5. Pelton SI. The global evolution of meningococcal epidemiology following the introduction of meningococcal vaccines. J Adolesc Health. 2016;59(2 Suppl):S3-11.

6. Borrow R, Alarcon P, Carlos J, et al. The global meningococcal initiative: global epidemiology, the impact of vaccines on meningococcal disease and the importance of herd protection. Expert Rev Vaccines. 2017;16:313-28.

7. Trotter CL, Lingani C, Fernandez K, et al. Impact of MenAfriVac in nine countries of the African meningitis belt, 2010-15: an analysis of surveillance data. Lancet Infect Dis. 2017;17:867-72.

8. Ladhani SN, Andrews N, Parikh SR, et al. Vaccination of infants with meningococcal group $B$ vaccine (4CMenB) in England. N Engl J Med. 2020;23(382): 309-17.

9. Keshavan P, Pellegrini M, Vadivelu-Pechai K, Nissen M. An update of clinical experience with the quadrivalent meningococcal ACWY-CRM conjugate vaccine. Expert Rev Vaccines. 2018;17:865-80.

10. Borrow R, Taha MK, Giuliani MM, Pizza M, Banzhoff A, Bekkat-Berkani R. Methods to evaluate serogroup B meningococcal vaccines: from predictions to real-world evidence. J Infect. 2020;81: 862-72.
11. Perez JL, Absalon J, Beeslaar J, et al. From research to licensure and beyond: clinical development of MenB-FHbp, a broadly protective meningococcal B vaccine. Expert Rev Vaccines. 2018;17:461-77.

12. Sall O, Olofsson E, Jacobsson S. High genomicbased predicted strain coverage among invasive meningococcal isolates when combining Bexsero and Trumenba vaccines. Vaccine. 2020;38:4374-8.

13. Clark SA, Borrow R. Herd protection against meningococcal disease through vaccination. Microorganisms. 2020;8:1675.

14. McMillan M, Chandrakumar A, Wang HLR, et al. Effectiveness of meningococcal vaccines at reducing invasive meningococcal disease and pharyngeal Neisseria meningitidis carriage: A systematic review and meta-analysis. Clin Infect Dis. 2020. https:// doi.org/10.1093/cid/ciaa1733 ((Online ahead of print)).

15. Ladhani SN, Ramsay $\mathrm{M}$, Borrow R, Riordan A, Watson JM, Pollard AJ. Enter B and W: two new meningococcal vaccine programmes launched. Arch Dis Child. 2016;101:91-5.

16. Campbell H, Edelstein M, Andrews N, Borrow R, Ramsay M, Ladhani S. Emergency meningococcal ACWY vaccination program for teenagers to control group W meningococcal disease, England, 2015-2016. Emerg Infect Dis. 2017;23:1184-7.

17. de Vries M, Claassen L, Te Wierik MJM, et al. Meningococcal W135 disease vaccination intent, the Netherlands, 2018-2019. Emerg Infect Dis. 2020;26:1420-9.

18. MacNeil JR, Blain AE, Wang X, Cohn AC. Current epidemiology and trends in meningococcal diseaseUnited States, 1996-2015. Clin Infect Dis. 2018;66: 1276-81.

19. Mbaeyi S, Pondo $\mathrm{T}$, Blain A, et al. Incidence of meningococcal disease before and after implementation of quadrivalent meningococcal conjugate vaccine in the United States. JAMA Pediatr. 2020;174:843-51.

20. Andrade AL, Minamisava R, Tomich LM, et al. Impact of meningococcal $\mathrm{C}$ conjugate vaccination four years after introduction of routine childhood immunization in Brazil. Vaccine. 2017;35:2025-33.

21. Villena R, Valenzuela MT, Bastias M, Santolaya ME. Meningococcal invasive disease by serogroup $\mathrm{W}$ and use of ACWY conjugate vaccines as control strategy in Chile. Vaccine. 2019;37:6915-21.

22. Archer BN, Chiu CK, Jayasinghe $\mathrm{SH}$, et al. Epidemiology of invasive meningococcal $\mathrm{B}$ disease in 
Australia, 1999-2015: priority populations for vaccination. Med J Aust. 2017;207:382-7.

23. Aye AMM, Bai X, Borrow R, et al. Meningococcal disease surveillance in the Asia-Pacific region (2020): the global meningococcal initiative. J Infect. 2020;81:698-711.

24. Borrow R, Caugant DA, Ceyhan $M$, et al. Meningococcal disease in the Middle East and Africa: findings and updates from the global meningococcal initiative. J Infect. 2017;75:1-11.

25. Taha MK, Presa J, Serra L. A review of the epidemiology of invasive meningococcal disease and vaccination strategies in North Africa. Int J Infect Dis. 2020;104:189-97.

26. Yezli S, Assiri AM, Alhakeem RF, Turkistani AM, Alotaibi B. Meningococcal disease during the Hajj and Umrah mass gatherings. Int $\mathrm{J}$ Infect Dis. 2016;47:60-4.

27. Yezli S. The threat of meningococcal disease during the Hajj and Umrah mass gatherings: a comprehensive review. Travel Med Infect Dis. 2018;24: 51-8.

28. Rajab MH. A master of public health with a concentration in mass gatherings health. Cureus. 2019;11:e5944.

29. Moore PS, Reeves MW, Schwartz B, Gellin BG, Broome CV. Intercontinental spread of an epidemic group A Neisseria meningitidis strain. Lancet. 1989;2:260-3.

30. Al-Gahtani YM, El Bushra HE, Al-Qarawi SM, AlZubaidi AA, Fontaine RE. Epidemiological investigation of an outbreak of meningococcal meningitis in Makkah (Mecca), Saudi Arabia, 1992. Epidemiol Infect. 1995;115:399-409.

31. Lingappa JR, Al-Rabeah AM, Hajjeh R, et al. Serogroup W-135 meningococcal disease during the Hajj, 2000. Emerg Infect Dis. 2003;9:665-71.

32. Wilder-Smith A, Goh KT, Barkham T, Paton NI. Hajj-associated outbreak strain of Neisseria meningitidis serogroup W135: estimates of the attack rate in a defined population and the risk of invasive disease developing in carriers. Clin Infect Dis. 2003;36:679-83.

33. Yezli S, Wilder-Smith A, Bin Saeed AA. Carriage of Neisseria meningitidis in the Hajj and Umrah mass gatherings. Int J Infect Dis. 2016;47:65-70.

34. Booy R, Gentile A, Nissen M, Whelan J, Abitbol V. Recent changes in the epidemiology of Neisseria meningitidis serogroup $\mathrm{W}$ across the world, current vaccination policy choices and possible future strategies. Hum Vaccin Immunother. 2019;15: 470-80.

35. Yezli S, Bin Saeed AA, Assiri AM, et al. Prevention of meningococcal disease during the Hajj and Umrah mass gatherings: past and current measures and future prospects. Int J Infect Dis. 2016;47:71-8.

36. Yezli S, Alotaibi B. Meningococcal disease during the Hajj and Umrah mass gatherings: A, C, W, Y may be covered but don't forget the B and X factors! Travel Med Infect Dis. 2017;15:5-7.

37. Yezli S, Assiri A, Nabulsi H, et al. From mass gatherings medicine to mass gatherings health: conclusions from the 3rd international conference on mass gatherings medicine, Riyadh, Kingdom of Saudi Arabia. Int J Infect Dis. 2018;66:128-30.

38. Yezli S, Gautret P, Assiri AM, Gessner BD, Alotaibi B. Prevention of meningococcal disease at mass gatherings: lessons from the Hajj and Umrah. Vaccine. 2018;36:4603-9.

39. Al-Mazrou YY, Al-Jeffri MH, Abdalla MN, Elgizouli SA, Mishskas AA. Changes in epidemiological pattern of Meningococcal disease in Saudi Arabia. Does it constitute a new challenge for prevention and control? Saudi Med J. 2004;25:1410-3.

40. Memish Z, Al Hakeem R, Al Neel O, Danis K, Jasir A, Eibach D. Laboratory-confirmed invasive meningococcal disease: effect of the Hajj vaccination policy, Saudi Arabia, 1995 to 2011. Euro Surveill. 2013;18:20581.

41. Kingdom of Saudi Arabia-Ministry of Health. Statistical yearbooks [2012-2019]. Available at: https:// www.moh.gov.sa/en/Ministry/Statistics/book/ Pages/default.aspx. Accessed 29 Apr 2021.

42. WHO. World Health Organisation. Defeating meningitis by 2030: baseline situation analysis. 2019. Available at: https://www.who.int/ immunization/research/BSA_20feb2019.pdf. Accessed 11 Jan 2021.

43. WHO. World Health Organisation. Defeating meningitis by 2030: a global road map. April 2020. Available at: https://www.who.int/immunization/ research/development/

DefeatingMeningitisRoadmap.pdf. Accessed 11 Jan 2021.

44. Shibl A, Tufenkeji H, Khalil M, Memish Z. Meningococcal leadership forum (MLF) expert group. Consensus recommendation for meningococcal disease prevention for Hajj and Umra pilgrimage/travel medicine. East Mediterr Health J. 2013;19:389-92. 
45. KSA-MoH. Immunization schedule 2020. Available at: https://www.moh.gov.sa/en/HealthAwareness/ EducationalContent/HealthTips/Documents/ Immunization-Schedule.pdf. Accessed 29 Apr 2021.

46. Muttalif AR, Presa JV, Haridy H, Gamil A, Serra LC, Cane A. Incidence and prevention of invasive meningococcal disease in global mass gathering events. Infect Dis Ther. 2019;8:569-79.

47. Al-Tawfiq JA, Memish ZA. The Hajj 2019 vaccine requirements and possible new challenges. J Epidemiol Glob Health. 2019;9:147-52.

48. El Kareh A, El Hage S, Safi S, Assouad E, Mokled E, Salameh P. Epidemiology of bacterial meningitis in Lebanon from 2011 to 2019. J Clin Neurosci. 2020;81:32-6.

49. Kurup PJ, Al-Abri S, Al-Mahrooqi S, et al. Epidemiology of meningitis in oman-implications for future surveillance. J Epidemiol Glob Health. 2018;8: 231-5.

50. Kam YW, Ahmed MY, Amrun SN, et al. Systematic analysis of disease-specific immunological signatures in patients with febrile illness from Saudi Arabia. Clin Transl Immunology. 2020;9:e1163.

51. Memish ZA, Al-Tawfiq JA, Almasri M, et al. Neisseria meningitidis nasopharyngeal carriage during the
Hajj: a cohort study evaluating the need for ciprofloxacin prophylaxis. Vaccine. 2017;35:2473-8.

52. Ceyhan M, Anis S, Htun-Myint L, Pawinski R, Soriano-Gabarro M, Vyse A. Meningococcal disease in the Middle East and North Africa: an important public health consideration that requires further attention. Int J Infect Dis. 2012;16:e574-82.

53. Zumla A, Memish ZA. Risk of antibiotic resistant meningococcal infections in Hajj pilgrims. BMJ. 2019;366:15260.

54. Acevedo R, Bai X, Borrow R, et al. The global meningococcal initiative meeting on prevention of meningococcal disease worldwide: epidemiology, surveillance, hypervirulent strains, antibiotic resistance and high-risk populations. Expert Rev Vaccines. 2019;18:15-30.

55. Willerton L, Lucidarme J, Campbell H, et al. Geographically widespread invasive meningococcal disease caused by a ciprofloxacin resistant nongroupable strain of the ST-175 clonal complex. J Infect. 2020;81:575-84.

56. KSA-MoH. Kingdom of Saudi Arabia-Ministry of Health. Statistical yearbook [2020]. Available at: https://www.moh.gov.sa/en/Ministry/Statistics/ book/Pages/default.aspx. Accessed 29 Apr 2021. 